\title{
Determining Discharge Characteristics and Limits of Heavy Metals and Metalloids for Wastewater Treatment Plants (WWTPs) in China Based on Statistical Methods
}

\author{
Yuhua Zhou ${ }^{1,2}$, Jing Lei ${ }^{1}$, Yu Zhang ${ }^{1}$, Jing Zhu ${ }^{1}$, Yanna Lu ${ }^{1}$, Xuefang Wu ${ }^{1, *}$ and Hao Fang ${ }^{3, *}$ \\ 1 Environmental Standards Institution, Chinese Research Academy of Environmental Sciences, \\ Beijing 100012, China; zhouyh@craes.org.cn (Y.Z.); leijing@craes.org.cn (J.L.); zhangyu@craes.org.cn (Y.Z.); \\ zhujing@craes.org.cn (J.Z.); luyn@craes.org.cn (Y.L.) \\ 2 College of Water Sciences, Beijing Normal University, Beijing 100875, China \\ 3 Beijing Municipal Research Institute of Environmental Protection, Beijing 100037, China \\ * Correspondence: wuxf@craes.org.cn (X.W.); fanghao@cee.cn (H.F.)
}

Received: 18 August 2018; Accepted: 11 September 2018; Published: 14 September 2018

\begin{abstract}
Industrial wastewater and sewage are both important sources of heavy metals and metalloids in urban wastewater treatment plants (WWTPs). China has made great efforts to control heavy metal and metalloid pollution by setting discharge limits for WWTPs. There is, however, limited discharge data and no systematic methodology for the derivation of discharge limits. In this study, 14 heavy metals and metalloids ( $\mathrm{Hg}$, alkyl mercury, $\mathrm{As}, \mathrm{Cd}, \mathrm{Cr}, \mathrm{Cr}^{6+}, \mathrm{Pb}, \mathrm{Ni}, \mathrm{Be}, \mathrm{Ag}, \mathrm{Cu}, \mathrm{Zn}$, $\mathrm{Mn}, \mathrm{Se}$ ) that are listed in the Discharge Standard of Pollutants for Municipal Wastewater Treatment Plant (GB 18918-2002) were selected for the analysis of discharge characteristics while using the supervised monitoring data from more than 800 WWTPs located in nine provinces in China. Of the 14 heavy metals and metalloids, all but alkyl mercury were detected in the discharge water. There was a high rate of detection of $\mathrm{As}, \mathrm{Cu}, \mathrm{Mn}$, Se, and there were some samples that exceeded the standard concentrations of $\mathrm{Cr}, \mathrm{Cr}^{6+}, \mathrm{Pb}$, and $\mathrm{Ni}$. Removal rates of $\mathrm{Hg}$, As, $\mathrm{Cd}, \mathrm{Cr}, \mathrm{Cr}^{6+}, \mathrm{Pb}, \mathrm{Ni}, \mathrm{Cu}$, $\mathrm{Zn}, \mathrm{Mn}$, and Se were higher than $40 \%$, comparable to values from other countries. $\mathrm{Hg}$ and As were selected to analyze the influencing factors of effluent and derive discharge limits of WWTPs using a statistical method, because these two metals had more detected data than other metals. The study used supervised monitoring data from Zhejiang WWTPs with 99 for $\mathrm{Hg}$ and 112 for As. Based on the delta-lognormal distribution, the results showed that geographic location was significantly closely correlated with $\mathrm{Hg}(P=0.027<0.05)$ and $\mathrm{As}(P \approx 0<0.05)$ discharge concentrations, while size (for $\mathrm{Hg} P=0.695>0.05$, for As $P=0.088>0.05)$ and influent concentration $\left(R^{2}<0.5\right)$ were not. Derived $\mathrm{Hg}$ and As discharge limits suggest that it is necessary to establish stricter discharge limits for WWTPs, which is more consistent with the real-world situation in China. The study here comprehensively researches the discharge characteristics of heavy metals and metalloids in effluent of WWTPs in China, and developed for the first time in China heavy metals and metalloids discharge limits based on statistical methods. The results may inform special discharge limit settings for WWTPs in China.
\end{abstract}

Keywords: heavy metal; metalloid; discharge characteristics; discharge standards; limits; statistical methods; urban wastewater treatment plants

\section{Introduction}

Industrial wastewater and sewage are major sources of heavy metals and metalloids at urban wastewater treatment plants (WWTPs). The European Union (EU) 2001 report on Pollutants in Urban 
Waste Water and Sewage Sludge [1] indicated that washing, drug use, and daily care were the main sources of heavy metal emissions. Oliver et al. [2] studied the heavy metals concentration in influent of WWTPs in Canada, which showed that the plants that received more industrial wastewater had higher concentrations of heavy metals than the plants that received only sewage, and Li et al. [3] had the similar conclusion when studied the influent of WWTPs received more industrial wastewater in China. Strengthening the monitoring and control of heavy metals and metalloids in WWTPs can play a substantial role in improving environmental quality and reducing environmental risks.

Like those of most countries, China's discharge standards have been designed to regulate the end-of-pipe wastewater discharges. The national standard "Integrated Wastewater Discharge Standard (GB 8978-1996)" [4] first established separate discharge limits for WWTPs. With development of environmental standard systems in the country, in 2002, the national discharge standard of WWTPs (GB 18918-2002) [5] was established, and it has played an important role in controlling water pollutants discharged from WWTPs. Because some of the WWTPs in China process industrial wastewater, GB 18918-2002 has set the limits for 14 heavy metals and metalloids to prevent environmental risks from both industrial wastewater and sewage, including total mercury $(\mathrm{Hg})$, alkyl mercury, total arsenic (As), total cadmium (Cd), total chromium $(\mathrm{Cr})$, hexavalent chromium $\left(\mathrm{Cr}^{6+}\right)$, total nickel $(\mathrm{Ni})$, total lead $(\mathrm{Pb})$, total silver $(\mathrm{Ag})$, total copper $(\mathrm{Cu})$, total zinc $(\mathrm{Zn})$, total beryllium $(\mathrm{Be})$, total manganese $(\mathrm{Mn})$, and total selenium (Se). However, the setting of limits for heavy metals and metalloids was based primarily on comparison to the limits for industrial wastewater control [6], without enough discharge data to analyze the difference to industrial wastewater. The limits setting also took some account of public health using times of surface water quality standards as the discharge limits considering the dilution [6] with a shortage of measured data to evaluate the real-world discharge level.

In recent years, China has made great efforts to collect discharge data, and these data, especially from WWTPs, have been used to reveal statistical distributions for pollutants discharge concentrations and evaluate the rationality of discharge standards [7-9]. However, these studies mainly concerned the conventional pollutants as chemical oxygen demand (COD) and ammonia nitrogen rather than heavy metals and metalloids or other toxic pollutants. Furthermore, there has been a lack of an overall perspective regarding heavy metals and metalloids discharge situations of WWTPs and a systematic method for deriving the discharge limits based on statistical approaches in China.

This study aims to comprehensively research the discharge characteristics of heavy metals and metalloids in effluent of WWTPs in China, and for the first time to derive discharge limits of heavy metals and metalloids based on measured data analysis. In the present study, 14 heavy metals and metalloids controlled in GB 18918-2002 were selected for analysis of the discharge characteristics, and the $\mathrm{Hg}$ and As with more detected data were selected to derive discharge limits of WWTPs using a statistical method. We also addressed factors that may affect $\mathrm{Hg}$ and As discharge concentrations from different WWTPs. The result of this study may provide guidance for revisions to standards for heavy metals and metalloids discharge in China.

\section{Data Source}

\subsection{Data Source}

In our study, supervised monitoring data carried out by local environmental protection authorities from Oct. 2016 to Mar. 2017 of concentrations of 14 heavy metals and metalloids discharged from more than 800 WWTPs located in nine provinces were used. These nine provinces were Jilin, Shanxi, Shandong, Zhejiang, Hubei, Hunan, Guangxi, Gansu, and Sichuan, which covered the northeast, northwest, north, east, south, and the southwest of China (Figure 1), including the higher heavy metal pollution level regions as Hunan, Guangxi, and Gansu [10]. The WWTPs from data sources of different sizes covered various ratios of industrial wastewater treated, classified as $<50 \%, 50-70 \%$ (including $50 \%$ ) and $\geq 70 \%$. In this way, the selected WWTPs were representative of Chinese WWTPs for locations, sizes, and ratios of the received industrial wastewater. 


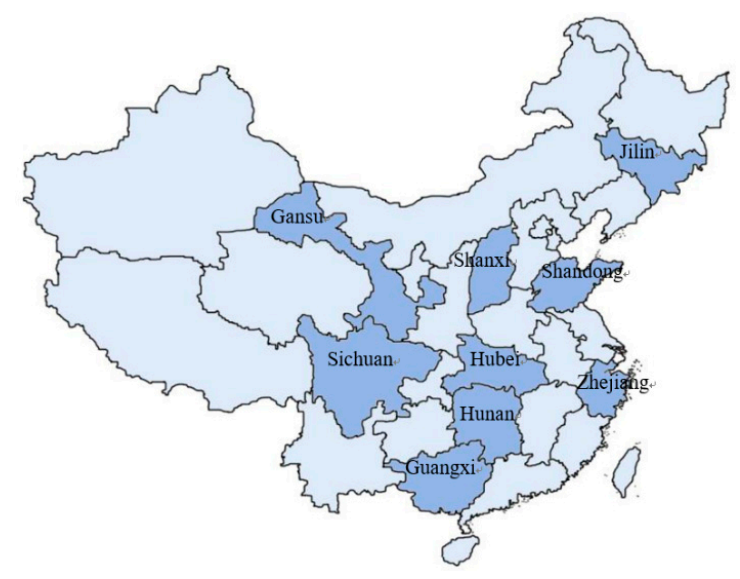

Figure 1. Location of nine investigated provinces of China.

$\mathrm{Hg}$ and As were selected to derive the discharge limits using statistical method because of higher ratios of detected data. When using the statistical method, there should be minimum data requirements of at least seven daily averages, and among these averages there should be at least three daily averages higher than the method detection limits [11]. Based on this principle, for the sake of more valid data, we adopted the supervised monitoring data from 2015 to 2017 of $\mathrm{Hg}$ and As discharged by WWTPs in Zhejiang Province as the data source, which were also representative of Chinese WWTPs. There were 99 WWTPs for Hg and 112 WWTPs for As conforming to the data principles.

\subsection{Data Analysis}

The data collected were daily average concentrations of 14 heavy metals and metalloids sampled once every $2 \mathrm{~h}$ for $24 \mathrm{~h}$ and mixed for analysis, while using the Environment Monitoring Analytical Method Standards in China (Table 1). We obtained the averages, maximums, minimums, mediums for each pollutant to study the discharge characteristics as rate of detection, rate of exceeding standards, and similar outcomes. In order to investigate the statistical distribution of heavy metals and metalloids discharged by WWTPs in China, the Hg and As with more available data and higher detected rate were selected for analysis while using Origin Pro 7.0 (OriginLab Corporation, Northampton, MA, USA). Based on the fitted statistical distribution, we used One-way analysis of variance to study the factors influencing discharge level by PASW Statistics 18.0 (IBM, New York, NY, USA), including locations, sizes, and influent concentrations level of WWTPs.

Table 1. Environment monitoring analytical methods used for analysis of 14 heavy metals and metalloids.

\begin{tabular}{cccc}
\hline No. & Pollutants & Method Source & Method Detection Limits (mg/L) \\
\hline 1 & $\mathrm{Hg}$ & HJ 694-2014 [12] & 0.00004 \\
2 & alkyl mercury & GB/T 14204-93 [13] & 0.00001 \\
3 & $\mathrm{As}$ & HJ 694-2014 [12] & 0.0003 \\
4 & $\mathrm{Cd}$ & GB 7471-87 [14] & 0.001 \\
5 & $\mathrm{Cr}$ & GB 7466-87 [15] & 0.004 \\
6 & $\mathrm{Cr}{ }^{6+}$ & GB 7467-87 [16] & 0.004 \\
7 & $\mathrm{~Pb}$ & GB/T 7470-1987 [17] & 0.01 \\
8 & $\mathrm{Ni}$ & GB 11912-89 [18] & 0.05 \\
9 & $\mathrm{Be}$ & HJ/T 59-2000 [19] & 0.00002 \\
10 & $\mathrm{Ag}$ & HJ 700-2014 [20] & 0.00004 \\
11 & $\mathrm{Cu}$ & HJ 485-2009 [21] & 0.01 \\
12 & $\mathrm{Zn}$ & GB 7475-87 [22] & 0.05 \\
13 & $\mathrm{Mn}$ & GB 11911-89 [23] & 0.01 \\
14 & $\mathrm{Se}$ & GB 11902-89 [24] & 0.00025 \\
\hline
\end{tabular}


Based on the fitted statistical distribution of heavy metals and metalloids discharge concentrations, discharge limits were derived by Equation (1) while using the long-term average (LTA) multiplied by the variability factor (VF). This equation has been used by the U.S. EPA in developing limits for many industries, such as the Organic Chemicals, Plastics and Synthetic Fibers (OCPSF) industry [25]. In this equation, the average of concentrations and the fluctuations in the treatment system are both considered, which reflects a state that most treatment systems are capable of achieving.

$$
\text { Limits }=\mathrm{LTA} \times \mathrm{VF}
$$

LTA is the target value that a plant's treatment system should achieve on an average basis. In the present study, we used the average concentrations to derive the Hg and As LTAs for each WWTP when considering both the undetected and detected data $[11,25]$. VF is the ratio of strong effluent to the average level, which expresses the relationship between large values and average treatment performance levels that a well-designed and operated treatment system should be capable of achieving all the time [11]. The U.S. EPA used the 99th and 95th percentiles to express the daily maximum and monthly average VFs, respectively $[11,25]$. Because the concept of monthly average was not used in China, we adopted the daily maximum 99th percentile VF in our study.

\section{Results and Discussion}

\subsection{The Heavy Metal and Metalloid Discharge Concentrations Level of WWTPs}

As shown (Table 2), there were 13 pollutants that were detected in the discharged water of WWTPs, except alkyl mercury. In relation to the detection rate, four pollutants were higher than $40 \%$, including $\mathrm{As}, \mathrm{Cu}, \mathrm{Mn}$, and Se, which indicated the higher exposure of these four pollutants in WWTPs of China. The detection rate of $\mathrm{Cr}, \mathrm{Hg}$ and $\mathrm{Zn}$ were higher than $20 \%$, which indicated the relative high exposure of the three pollutants also. In the point view of discharge concentrations, among the 13 detected pollutants, there were cases of over the standard for four pollutants, including $\mathrm{Cr}, \mathrm{Cr}^{6+}, \mathrm{Pb}$, and $\mathrm{Ni}$, with the standard exceeding ratio being $0.9 \%, 0.4 \%, 0.1 \%$, and $17.0 \%$, respectively, which most occurred in the WWTPs received wastewater from electroplate plants. The ratios of average concentrations to discharge limits in GB 18918-2002 for other nine pollutants were between 0.02 and 0.4, which were 1-2 orders of magnitude lower than the limits and indicated the low level of discharge concentrations. The ratios of average concentrations to mediums were all $\geq 1.0$ for 13 pollutants, which indicated that most of the concentrations were lower than the average. When comparing the discharge concentrations of WWTPs in China to other countries, they were equivalent (Table 3).

Table 2. Discharge concentrations of 14 heavy metals and metalloids in wastewater treatment plants (WWTPs) of China.

\begin{tabular}{|c|c|c|c|c|c|c|c|c|c|}
\hline \multirow{2}{*}{ No. } & \multirow[b]{2}{*}{ Pollutant } & \multirow{2}{*}{$\begin{array}{l}\text { Number of } \\
\text { WWTPs }\end{array}$} & \multirow{2}{*}{$\begin{array}{c}\text { Number of } \\
\text { Samples }\end{array}$} & \multirow{2}{*}{$\begin{array}{l}\text { Detection } \\
\text { Rate }\end{array}$} & \multicolumn{4}{|c|}{ Data of Detection $(\mathrm{mg} / \mathrm{L})$} & \multirow{2}{*}{$\begin{array}{l}\text { Discharge Limits in GB } \\
18918-2002(\mathrm{mg} / \mathrm{L})\end{array}$} \\
\hline & & & & & $\operatorname{Max}$ & Min & Average & Medium & \\
\hline 1 & $\mathrm{Hg}$ & 872 & 1080 & $26.7 \%$ & 0.00109 & 0.00004 & 0.00017 & 0.00011 & 0.001 \\
\hline 2 & $\begin{array}{c}\text { alkyl } \\
\text { mercury }\end{array}$ & 438 & 498 & $0 \%$ & -1 & -1 & $-^{1}$ & -1 & Non-detected \\
\hline 3 & As & 858 & 925 & $58.2 \%$ & 0.064 & 0.0003 & 0.0023 & 0.0012 & 0.1 \\
\hline 4 & $\mathrm{Cd}$ & 873 & 786 & $6.0 \%$ & 0.009 & 0.001 & 0.004 & 0.004 & 0.01 \\
\hline 5 & $\mathrm{Cr}$ & 864 & 761 & $31.3 \%$ & 0.44 & 0.004 & 0.026 & 0.016 & 0.1 \\
\hline 6 & $\mathrm{Cr}^{6+}$ & 881 & 1120 & $15.9 \%$ & 0.118 & 0.004 & 0.014 & 0.009 & 0.05 \\
\hline 7 & $\mathrm{~Pb}$ & 873 & 877 & $6.2 \%$ & 0.11 & 0.01 & 0.04 & 0.03 & 0.1 \\
\hline 8 & $\mathrm{Ni}$ & 122 & 124 & $14.5 \%$ & 0.4 & 0.06 & 0.18 & 0.14 & 0.05 \\
\hline 9 & $\mathrm{Be}$ & 32 & 43 & $18.6 \%$ & 0.0001 & 0.00002 & 0.00004 & 0.00004 & 0.002 \\
\hline 10 & $\mathrm{Ag}$ & 32 & 15 & $6.7 \%$ & 0.00023 & 0.00023 & 0.00023 & 0.00023 & 0.1 \\
\hline 11 & $\mathrm{Cu}$ & 104 & 50 & $44.0 \%$ & 0.36 & 0.01 & 0.11 & 0.09 & 0.5 \\
\hline 12 & $\mathrm{Zn}$ & 63 & 63 & $22.2 \%$ & 0.37 & 0.05 & 0.14 & 0.11 & 1.0 \\
\hline 13 & $\mathrm{Mn}$ & 37 & 63 & $41.3 \%$ & 0.470 & 0.012 & 0.128 & 0.060 & 2.0 \\
\hline 14 & Se & 24 & 43 & $41.9 \%$ & 0.02530 & 0.00025 & 0.00444 & 0.00050 & 0.1 \\
\hline
\end{tabular}


Table 3. Comparison of discharge concentrations of 14 heavy metals and metalloids in WWTPs of China and other countries.

\begin{tabular}{|c|c|c|c|c|c|}
\hline No. & Pollutants & Countries & Concentration $(\mu \mathrm{g} / \mathrm{L})$ & Reference & This Study $(\mu \mathrm{g} / \mathrm{L})$ \\
\hline \multirow{2}{*}{1} & \multirow{2}{*}{$\mathrm{Hg}$} & U.S. & $0.023 \pm 0.016$ & [26] & \multirow{2}{*}{ 0.04-1.09 } \\
\hline & & Brazil & $0-0.24$ & {$[27]$} & \\
\hline 2 & alkyl mercury & U.S. & $0.00153 \pm 0.00093$ & [26] & Undetected \\
\hline \multirow[t]{2}{*}{3} & As & Italy & $0.5-9.2$ & [28] & $0.3-64$ \\
\hline & & Italy & $0.1-1.6$ & {$[28]$} & \\
\hline \multirow[t]{3}{*}{4} & $\mathrm{Cd}$ & Brazil & $0.04-0.11$ & [27] & $1-9$ \\
\hline & & Canada & $1-20$ & [2] & \\
\hline & & Brazil & $1.68-13.53$ & {$[27]$} & \\
\hline \multirow[t]{2}{*}{5} & $\mathrm{Cr}$ & Canada & $10-710$ & [2] & $4-440$ \\
\hline & & Poland & $10 \pm 10$ & [29] & \\
\hline \multirow[t]{2}{*}{6} & $\mathrm{Cr}^{6+}$ & U.S. & $1 \pm 0.6$ & [30] & $4-118$ \\
\hline & & Brazil & $4.22-76.42$ & [27] & \\
\hline \multirow[t]{2}{*}{7} & $\mathrm{~Pb}$ & Canada & $50-200$ & [2] & $10-110$ \\
\hline & & Poland & $10 \pm 10$ & {$[29]$} & \\
\hline \multirow{2}{*}{8} & & Canada & $30-670$ & [2] & \\
\hline & $\mathrm{Ni}$ & Poland & $20 \pm 10$ & {$[29]$} & $60-400$ \\
\hline 9 & $\mathrm{Be}$ & Canada & Undetected & [2] & $0.02-0.1$ \\
\hline \multirow{3}{*}{10} & & Canada & $<10$ & [2] & \\
\hline & $\mathrm{Ag}$ & Poland & 10 & {$[29]$} & 0.23 \\
\hline & & Brazil & $2.13-19.87$ & [27] & \\
\hline \multirow[t]{3}{*}{11} & $\mathrm{Cu}$ & Canada & $20-100$ & [2] & $10-360$ \\
\hline & & Poland & $10 \pm 20$ & [29] & \\
\hline & & Italy & $24-238$ & [28] & \\
\hline \multirow{3}{*}{12} & & Brazil & $22.80-76.25$ & [27] & \\
\hline & $\mathrm{Zn}$ & Canada & $40-560$ & [2] & $50-370$ \\
\hline & & Poland & $50 \pm 90$ & [29] & \\
\hline \multirow{2}{*}{13} & & Brazil & $35.55-73.41$ & [27] & \\
\hline & $\mathrm{Mn}$ & Canada & $20-220$ & [2] & $12-470$ \\
\hline 14 & Se & Spain & $0.133 \pm 0.085$ & [31] & $0.25-25.3$ \\
\hline
\end{tabular}

\subsection{Removal Rate of Heavy Metals and Metalloids in WWTPs in China}

When researching the removal rate of heavy metals and metalloids in WWTPs, the discharge concentrations of undetected data were calculated with the Equation (2). The removal rates of 14 heavy metals and metalloids are shown in Table 4.

$$
\text { Discharge concentration of undetected data }=\frac{1}{2} \times \mathrm{MDL}
$$

where:

MDL-Method Detection Limit.

Table 4. Removal rates of heavy metals in WWTPs of China.

\begin{tabular}{ccc}
\hline No. & Pollutant & Average Removal Rate \\
\hline 1 & $\mathrm{Hg}$ & $57.4 \%$ \\
2 & alkyl & -1 \\
3 & mercury & $47.3 \%$ \\
4 & $\mathrm{As}$ & $61.0 \%$ \\
5 & $\mathrm{Cd}$ & $69.8 \%$ \\
6 & $\mathrm{Cr}$ & $64.4 \%$ \\
7 & $\mathrm{Cr} 6+$ & $66.4 \%$ \\
8 & $\mathrm{~Pb}$ & $50.8 \%$ \\
9 & $\mathrm{Ni}$ & $25.6 \%$ \\
10 & $\mathrm{Be}$ & -1 \\
11 & $\mathrm{Ag}$ & $53.1 \%$ \\
12 & $\mathrm{Cu}$ & $65.5 \%$ \\
13 & $\mathrm{Zn}$ & $42.8 \%$ \\
14 & $\mathrm{Mn}$ & $63.3 \%$ \\
\hline 1 “ & $\mathrm{Se}$ & indicates that the data is not enough to get the results.
\end{tabular}


As noted in Table 4, the removal rates of $\mathrm{Hg}, \mathrm{Cd}, \mathrm{Cr}, \mathrm{Cr}^{6+}, \mathrm{Pb}, \mathrm{Ni}, \mathrm{Cu}, \mathrm{Zn}$, and $\mathrm{Se}$ in the WWTPs are higher than $50 \%$ ranging from $50.8 \%$ to $69.8 \%$, while the removal rate of As and Mn are $47.3 \%$ and $42.8 \%$, respectively. The rate of Be is lower than $30 \%$.

Removal rates of heavy metals and metalloids in China's WWTPs were comparable to those reported in research findings in other countries. Obarska-Pempkowiak [32] showed that the removal rate of zinc in WWTPs was $50 \%$, copper was $60 \%$, lead was $79 \%$, and cadmium was $80 \%$. Olive et al. [2] found that the removal rate of aluminum, cadmium, chromium, copper, iron, lead, mercury, and zinc were all higher than 70\% in Canadian WWTPs, but they reported lower values for manganese, nickel and strontium. Kulbat et al. [29] found that the rate of zinc removal was $78.1 \%-86.2 \%$, copper was $78.1 \%-93.2 \%$, chromium was $45.3 \%-66.7 \%$, silver was $28.3 \%-66.7 \%$, lead was $48 \%-83 \%$ in Polish WWTPs, and these research results indicated higher removal rate of heavy metals.

It is difficult to discuss the influence of treatment process to the removal rate of heavy metals and metalloids under any but the most controlled conditions. Most metals in wastewater are soluble, but if mixed with sewage, the changes in $\mathrm{pH}$ and the act of mixing with other organics can render many types of metals insoluble and convert them to sludge, leading to high removal rates in wastewater [2]. The removal rate is affected by many factors, including type of metal, concentration in the influent, interactions with microbes in the sewage treatment system, and the treatment processes that are employed by the WWTPs [29].

\subsection{Statistical Distribution of Heavy Metal and Metalloid Discharge Concentrations}

Among the $1080 \mathrm{Hg}$ discharge figures that were collected from 872 WWTPs, 792 indicated that no mercury was detected and 288 indicated mercury had been detected. Among the 925 As discharge data from 858 WWTPs, 387 were not detected, while 537 were detected. While using the detected daily average data, as shown in Figures 2 and 3, it the lognormal distribution was visible for both $\mathrm{Hg}$ and As detected according to the fitting lines with the logarithm of $\mathrm{Hg}$ or As concentrations on the horizontal $x$-axis against the normal probabilities on the vertical $y$-axis. This distribution was also verified while using the P-P graph test (Figures 4 and 5) with the fitting lines of cumulative probability of monitoring data after logarithmic transformation against the expected cumulative probability. The lognormal distribution of effluent concentrations is also consistent with other research $[7,33]$.

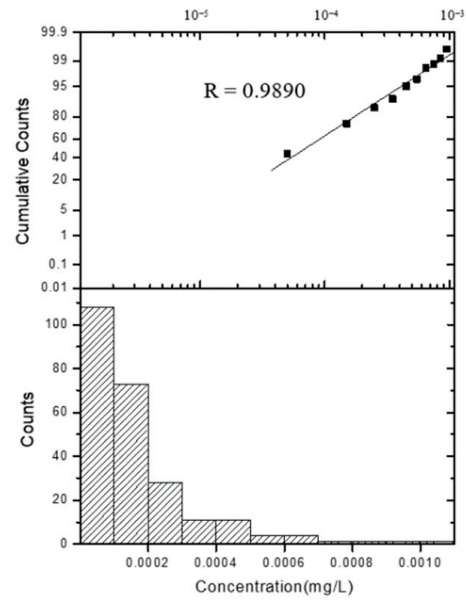

Figure 2. Statistical distribution of detected daily average concentrations of $\mathrm{Hg}$ of the WWTPs. 


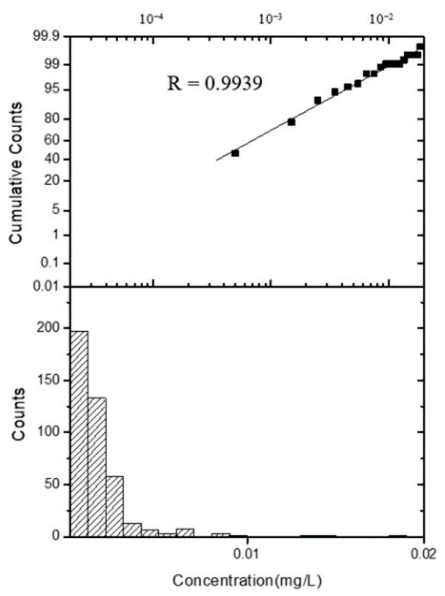

Figure 3. Statistical distribution of detected daily average concentrations of As of the WWTPs.

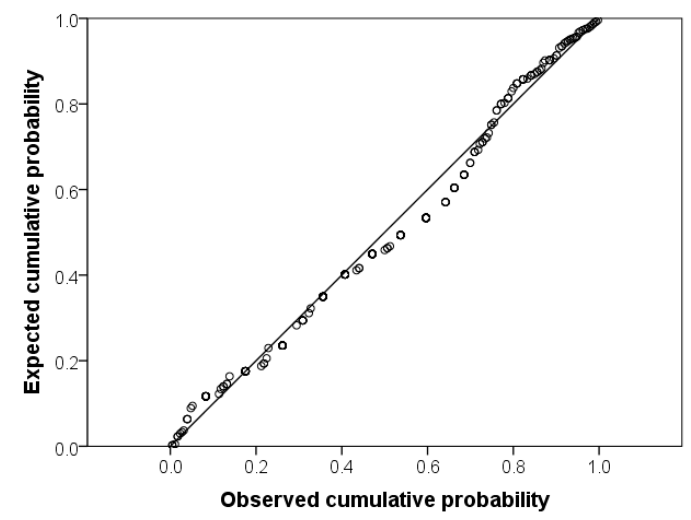

Figure 4. P-P graph of logarithm of the detected daily average concentrations of $\mathrm{Hg}$.

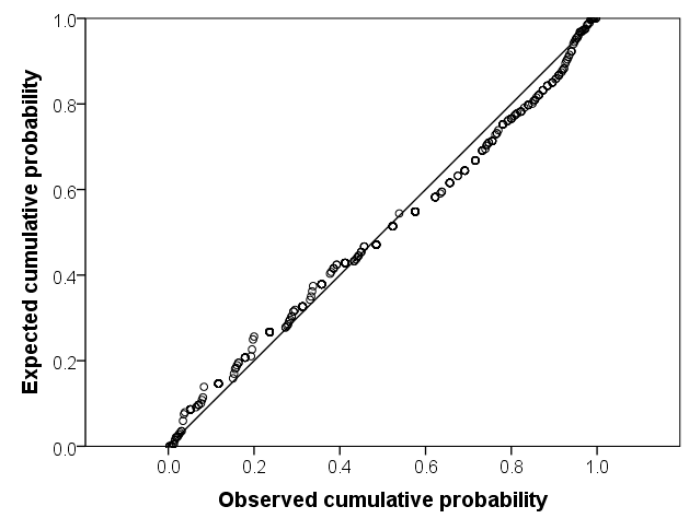

Figure 5. P-P graph of logarithm of the detected daily average concentrations of As.

When considering some of the undetected data, the delta-lognormal distribution provides a reasonable and practical basis for further analysis of the heavy metal and metalloid data and determining the discharge limits, which is in accordance with the EPA regulations $[11,25,34]$. The delta-lognormal distribution consists of two parts, undetected numbers and detected numbers conforming to the lognormal distribution. The distribution function of delta-lognormal distribution can be expressed as $[11,25,34]$ :

$$
f(x)=\delta I\left(x_{0}\right)+(1-\delta) g(x)
$$

where:

$\delta$-the ratio of non-detected, $0 \leq \delta \leq 1$; when $x_{0}=\mathrm{ND}, I\left(x_{0}\right)=1$, or else $I\left(x_{0}\right)=0$; $g(x)$ - the function of lognormal distribution. 


\subsection{Factors Influencing Heavy Metal and Metalloid Discharge Concentrations}

There are some data requirements for One-way analysis of variance, conforming to normal distribution, independence, and homogeneity variance. The logarithm of detected data have been shown to fit normal distribution, and because the data were all from independent samples, they met the independence requirement. The homogeneity of variance test was taken with the One-way analysis of variance, if any sample did not pass the test, the Kruskal-Wallis test was used for analysis.

\subsubsection{Regional Differences}

Discharge concentrations of heavy metals and metalloids in WWTPs from nine provinces were analyzed. Figure 6 indicates that the Hg concentrations from Shandong, Zhejiang, Guangxi, Gansu, and Shanxi WWTPs were relatively high with about 50\% WWTPs in these regions being higher than $0.0001 \mathrm{mg} / \mathrm{L}$. Figure 7 indicates that the As concentrations from Zhejiang, Hunan, Guangxi, Gansu, and Shanxi WWTPs were relatively high with average concentrations of As in these regions higher than $0.002 \mathrm{mg} / \mathrm{L}$. According to China's “Environment Statistical Annual Report 2015" [10] of China, Guangxi, and Gansu are top two regions in which more $\mathrm{Hg}$ was discharged in wastewater, because of large number of facilities that engage in nonferrous metallurgy, chemical raw materials, and chemical products producing. This was consistent with the results of data analysis.

The effect of geographical location on $\mathrm{Hg}$ and As discharge concentration levels in WWTPs was analyzed while using One-way analysis of variance with the independent variable being the logarithm of concentration data, and the variables being different regions. Because the data did not pass the homogeneity of variance test, Kruskal-Wallis test was used and the results showed there to be significant differences in $\mathrm{Hg}(P=0.027<0.05)$ and $\mathrm{As}(P \approx 0<0.05)$ discharge concentrations for different regions, with the Hunan Province showing significant differences from all other regions.

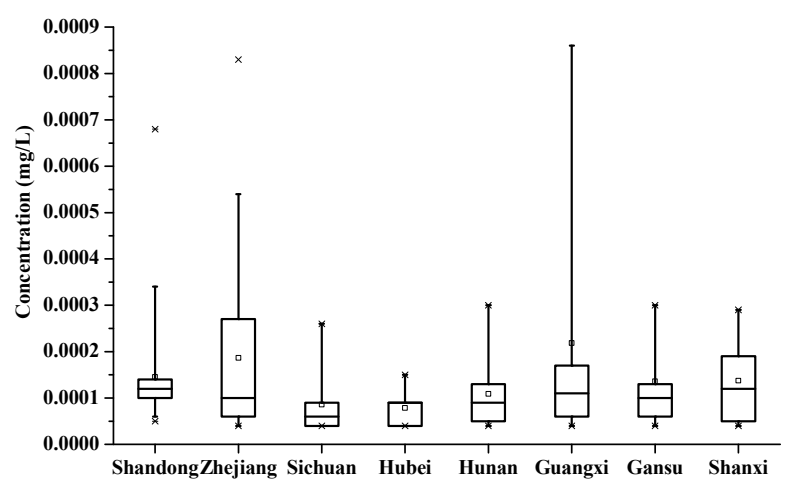

Figure 6. Boxplot of discharge concentrations of $\mathrm{Hg}$ from different regions WWTPs. Note: Because there was not enough data from Jilin WWTPs, so there was no boxplot for Jilin. " $\square$ " stands for average value, and " $\times$ " stands for $95 \%$ percentiles.

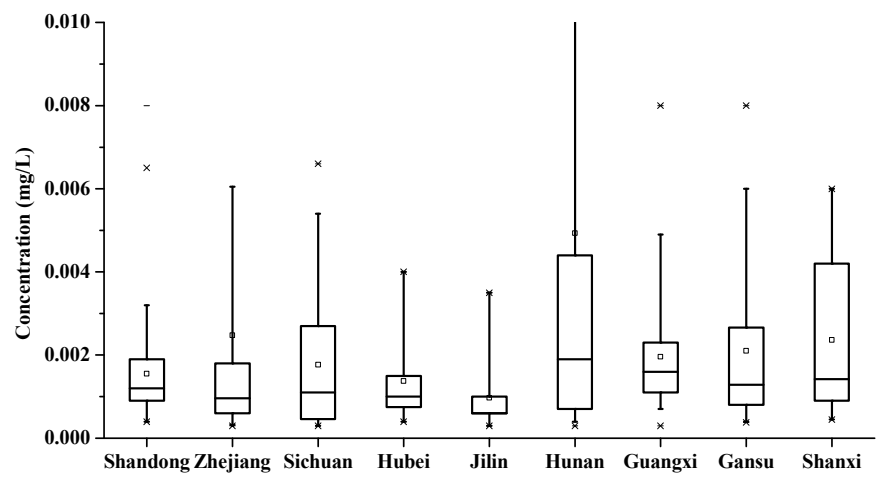

Figure 7. Boxplot of discharge concentrations of As from different regions WWTPs. “ $\square$ " stands for average value, and " $\times$ " stands for $95 \%$ percentiles. 


\subsubsection{Scale Differences}

The numbers of samples from WWTPs in nine provinces that consisted of the scale information were 95 for $\mathrm{Hg}$ and 187 for As. Among these data, the average concentrations of $\mathrm{Hg}$ and As for large-scale (treatment capacity $\geq 0.1$ million $\mathrm{m}^{3} /$ day), mid-scale $\left(10\right.$ thousand $\mathrm{m}^{3} /$ day $\leq$ treatment capacity $<0.1$ million $\mathrm{m}^{3} /$ day), and small-scale (treatment capacity $<10$ thousand $\mathrm{m}^{3} /$ day) of WWTPs are shown in Table 5. We can find the Hg concentrations from different scale WWTPs are close, but As concentrations from large scale are higher. The latter may be attributable to 6 of the 18 large-scale WWTPs with high influent concentrations. The scale factor is not significant to $\mathrm{Hg}(P=0.695>0.05)$ according to the One-way analysis of variance and not significant for As $(P=0.088>0.05)$ either, according to Kruskal-Wallis test.

Table 5. Discharge concentrations of $\mathrm{Hg}$ and As for different scales of WWTPs.

\begin{tabular}{cccc}
\hline Pollutant & Scale of WWTPs & Number of Detected Samples & Average Discharge Concentration(mg/L) \\
\hline \multirow{3}{*}{$\mathrm{Hg}$} & Large-scale & 10 & 0.00013 \\
& Mid-scale & 75 & 0.00016 \\
& Small-scale & 10 & 0.00016 \\
\multirow{3}{*}{ As } & Large-scale & 18 & 0.0063 \\
& Mid-scale & 148 & 0.0017 \\
& Small-scale & 21 & 0.0010 \\
\hline
\end{tabular}

\subsubsection{Relationship between the Concentrations of Influent and Effluent}

The relationship between the concentrations of influent and effluent was analyzed (Figures 8 and 9). The results show that the linear relationship between the concentrations of influent and effluent is weak $\left(R^{2}<0.5\right)$. Gbondo-Tugbawa et al. [26] also reported that there is no significant relationship between the mercury influent concentration and effluent.

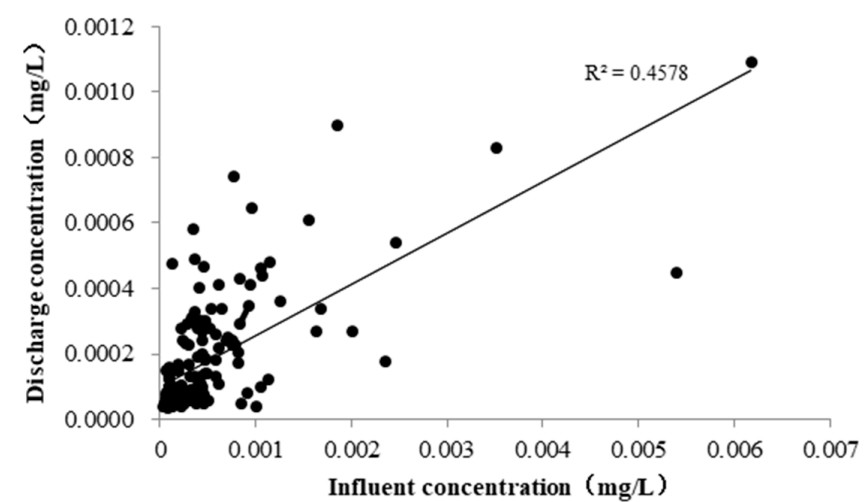

Figure 8. Relationship between the concentration of influent and effluent for $\mathrm{Hg}$ from WWTPs.

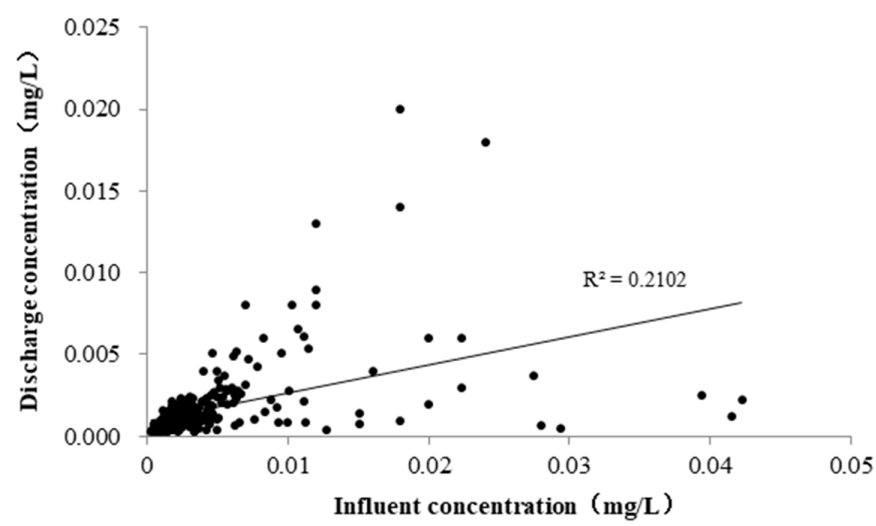

Figure 9. Relationship between the concentration of influent and effluent for As from WWTPs. 
Research has been performed on influent and effluent concentration data of $\mathrm{Hg}$ and As from WWTPs in Zhejiang Province. From the Table 6 we can conclude that the standard deviation of $\mathrm{Hg}$ and As influent concentration is higher than the effluent concentration, which suggests that the biochemical treatment system could play a role in buffering the fluctuation of heavy metals and metalloids, such as $\mathrm{Hg}$ and As, and there was the same conclusion in Balogh et al. [35] and Li et al. [36] research, which could explain the weak linear relationship between influent and effluent concentrations.

Table 6. Average of standard deviations of influent and effluent for $\mathrm{Hg}$ and As.

\begin{tabular}{ccc}
\hline \multirow{2}{*}{ Pollutants } & \multicolumn{2}{c}{ Average of Standard Deviation $(\mathbf{m g} / \mathbf{L})$} \\
\cline { 2 - 3 } & Influent & Effluent \\
\hline $\mathrm{Hg}$ & 0.0115 & 0.0001 \\
$\mathrm{As}$ & 0.0115 & 0.0017 \\
\hline
\end{tabular}

\subsection{Discharge Limits of $\mathrm{Hg}$ and As}

\subsubsection{Long-Time Averages}

Based on the delta-lognormal distribution, the long-time averages were calculated, as follows $[11,25,34]$ :

$$
\operatorname{LTA}_{j}=\delta D+(1-\delta) \frac{\sum_{i=1}^{n} X_{i}}{n}
$$

where:

$\mathrm{LTA}_{j}$ - the long-time average of heavy metal or metalloid of $\mathrm{WWTP}_{j} ;$

$\delta$-the rate of below method detection limit;

$D$-method detection limit;

$X_{i}$-the concentration higher than method detection limit;

$n$-the number of concentration data up the method detection limit.

According to the equation above, the long-time averages of $\mathrm{Hg}$ for 99 WWTPs and As for 112 WWTPs are shown in Tables 7 and 8. The LTAs for $\mathrm{Hg}$ are from 0.00004 to $0.00081 \mathrm{mg} / \mathrm{L}$ with an average of $0.00015 \mathrm{mg} / \mathrm{L}$ and medium of $0.00009 \mathrm{mg} / \mathrm{L}$. The LTAs for As are from 0.0003 to $0.0250 \mathrm{mg} / \mathrm{L}$ with an average of $0.0021 \mathrm{mg} / \mathrm{L}$ and medium of $0.0012 \mathrm{mg} / \mathrm{L}$.

We can conclude that the LTAs of $\mathrm{Hg}$ and As are close to the level of surface water quality limits Grade I III in "Surface water environmental quality standards" (GB 3838-2002) [37], and also comparable to the results of other works. For example, research shows the influent concentration of $\mathrm{Hg}$ was about $0.001 \mathrm{mg} / \mathrm{L}$, varying with time and location [38]. The average influent concentration of $\mathrm{Hg}$ of 3 WWTPs in Canada was $0.000061 \mathrm{mg} / \mathrm{L}$, and the discharge concentrations were from $0.000003-0.000014 \mathrm{mg} / \mathrm{L}$ [39]. Some studies in China also showed that the $\mathrm{Hg}$ concentrations from sewage were $0.0002-0.0024 \mathrm{mg} / \mathrm{L}$, and the discharge concentrations were $0.00001-0.000029 \mathrm{mg} / \mathrm{L}$, which was much lower than the limits in GB 18918-2002 [5]. Lu et al. [40] studied on the As concentration of WWTPs in Chongqing Province, showing that the influent concentration was about $0.00105 \mathrm{mg} / \mathrm{L}$, and the discharge concentration was about $0.0007 \mathrm{mg} / \mathrm{L}$. 
Table 7. LTAs of $\mathrm{Hg}$ for 99 WWTPs.

\begin{tabular}{|c|c|c|c|c|c|c|c|}
\hline $\begin{array}{c}\text { No. of } \\
\text { WWTPs }\end{array}$ & $\begin{array}{c}\text { Number of } \\
\text { Samples }\end{array}$ & $\begin{array}{c}\text { Rate of } \\
\text { Undetected }\end{array}$ & $\begin{array}{c}\text { LTA } \\
(\mathrm{mg} / \mathrm{L})\end{array}$ & $\begin{array}{c}\text { No. of } \\
\text { WWTPs }\end{array}$ & $\begin{array}{l}\text { Number of } \\
\text { Samples }\end{array}$ & $\begin{array}{c}\text { Rate of } \\
\text { Undetected }\end{array}$ & $\begin{array}{c}\text { LTA } \\
(\mathrm{mg} / \mathrm{L})\end{array}$ \\
\hline 1 & 38 & $76.3 \%$ & 0.00007 & 51 & 18 & $66.7 \%$ & 0.00011 \\
\hline 2 & 34 & $76.5 \%$ & 0.00010 & 51 & 18 & $44.4 \%$ & 0.00005 \\
\hline 3 & 23 & $47.8 \%$ & 0.00041 & 51 & 7 & $42.9 \%$ & 0.00007 \\
\hline 4 & 25 & $44.0 \%$ & 0.00008 & 51 & 18 & $77.8 \%$ & 0.00005 \\
\hline 5 & 22 & $27.3 \%$ & 0.00008 & 51 & 18 & $72.2 \%$ & 0.00005 \\
\hline 6 & 21 & $47.6 \%$ & 0.00012 & 51 & 17 & $23.5 \%$ & 0.00014 \\
\hline 7 & 21 & $38.1 \%$ & 0.00007 & 51 & 15 & $40.0 \%$ & 0.00014 \\
\hline 8 & 16 & $25.0 \%$ & 0.00005 & 51 & 15 & $60.0 \%$ & 0.00011 \\
\hline 9 & 23 & $65.2 \%$ & 0.00007 & 51 & 10 & $70.0 \%$ & 0.00004 \\
\hline 10 & 23 & $65.2 \%$ & 0.00008 & 51 & 15 & $46.7 \%$ & 0.00019 \\
\hline 11 & 24 & $66.7 \%$ & 0.00009 & 51 & 15 & $53.3 \%$ & 0.00011 \\
\hline 12 & 14 & $71.4 \%$ & 0.00008 & 51 & 14 & $42.9 \%$ & 0.00008 \\
\hline 13 & 21 & $19.0 \%$ & 0.00027 & 51 & 11 & $0.0 \%$ & 0.00032 \\
\hline 14 & 10 & $30.0 \%$ & 0.00008 & 51 & 13 & $69.2 \%$ & 0.00006 \\
\hline 15 & 22 & $81.8 \%$ & 0.00005 & 51 & 13 & $0.0 \%$ & 0.00008 \\
\hline 16 & 8 & $12.5 \%$ & 0.00033 & 51 & 12 & $41.7 \%$ & 0.00009 \\
\hline 17 & 22 & $54.5 \%$ & 0.00006 & 51 & 12 & $58.3 \%$ & 0.00008 \\
\hline 18 & 13 & $15.4 \%$ & 0.00010 & 51 & 12 & $75.0 \%$ & 0.00008 \\
\hline 19 & 10 & $40.0 \%$ & 0.00011 & 51 & 10 & $40.0 \%$ & 0.00006 \\
\hline 20 & 22 & $63.6 \%$ & 0.00005 & 51 & 10 & $20.0 \%$ & 0.00028 \\
\hline 21 & 11 & $27.3 \%$ & 0.00009 & 51 & 10 & $20.0 \%$ & 0.00038 \\
\hline 22 & 22 & $22.7 \%$ & 0.00008 & 51 & 10 & $40.0 \%$ & 0.00015 \\
\hline 23 & 15 & $13.3 \%$ & 0.00045 & 51 & 8 & $50.0 \%$ & 0.00005 \\
\hline 24 & 22 & $45.5 \%$ & 0.00008 & 51 & 9 & $0.0 \%$ & 0.00052 \\
\hline 25 & 21 & $47.6 \%$ & 0.00006 & 51 & 9 & $11.1 \%$ & 0.00076 \\
\hline 26 & 21 & $61.9 \%$ & 0.00007 & 51 & 9 & $0.0 \%$ & 0.00026 \\
\hline 27 & 18 & $77.8 \%$ & 0.00005 & 51 & 9 & $22.2 \%$ & 0.00009 \\
\hline 28 & 21 & $23.8 \%$ & 0.00007 & 51 & 9 & $0.0 \%$ & 0.00016 \\
\hline 29 & 8 & $0.0 \%$ & 0.00008 & 51 & 7 & $0.0 \%$ & 0.00024 \\
\hline 30 & 18 & $0.0 \%$ & 0.00025 & 51 & 9 & $0.0 \%$ & 0.00015 \\
\hline 31 & 18 & $72.2 \%$ & 0.00005 & 51 & 9 & $0.0 \%$ & 0.00016 \\
\hline 32 & 21 & $38.1 \%$ & 0.00011 & 51 & 9 & $66.7 \%$ & 0.00009 \\
\hline 33 & 21 & $33.3 \%$ & 0.00010 & 51 & 9 & $0.0 \%$ & 0.00014 \\
\hline 34 & 21 & $19.0 \%$ & 0.00011 & 51 & 9 & $11.1 \%$ & 0.00025 \\
\hline 35 & 21 & $23.8 \%$ & 0.00007 & 51 & 9 & $22.2 \%$ & 0.00006 \\
\hline 36 & 18 & $0.0 \%$ & 0.00025 & 51 & 8 & $25.0 \%$ & 0.00006 \\
\hline 37 & 17 & $0.0 \%$ & 0.00022 & 51 & 8 & $0.0 \%$ & 0.00017 \\
\hline 38 & 11 & $0.0 \%$ & 0.00034 & 51 & 7 & $0.0 \%$ & 0.00021 \\
\hline 39 & 18 & $0.0 \%$ & 0.00027 & 51 & 9 & $22.2 \%$ & 0.00009 \\
\hline 40 & 21 & $57.1 \%$ & 0.00008 & 51 & 8 & $50.0 \%$ & 0.00006 \\
\hline 41 & 21 & $57.1 \%$ & 0.00011 & 51 & 8 & $0.0 \%$ & 0.00029 \\
\hline 42 & 21 & $9.5 \%$ & 0.00019 & 51 & 9 & $22.2 \%$ & 0.00005 \\
\hline 43 & 21 & $61.9 \%$ & 0.00005 & 51 & 9 & $11.1 \%$ & 0.00026 \\
\hline 44 & 21 & $57.1 \%$ & 0.00005 & 51 & 9 & $33.3 \%$ & 0.00025 \\
\hline 45 & 21 & $52.4 \%$ & 0.00018 & 51 & 9 & $55.6 \%$ & 0.00022 \\
\hline 46 & 20 & $60.0 \%$ & 0.00006 & 51 & 8 & $50.0 \%$ & 0.00010 \\
\hline 47 & 21 & $76.2 \%$ & 0.00006 & 51 & 7 & $28.6 \%$ & 0.00005 \\
\hline 48 & 18 & $5.6 \%$ & 0.00018 & 51 & 8 & $62.5 \%$ & 0.00013 \\
\hline 49 & 18 & $77.8 \%$ & 0.00006 & 51 & 7 & $28.6 \%$ & 0.00006 \\
\hline 50 & 18 & $33.3 \%$ & 0.00081 & & & & \\
\hline
\end{tabular}

Table 8. LTAs of As for 112 WWTPs.

\begin{tabular}{cccc|cccc}
\hline $\begin{array}{c}\text { No. of } \\
\text { WWTPs }\end{array}$ & $\begin{array}{c}\text { Number of } \\
\text { Samples }\end{array}$ & $\begin{array}{c}\text { Rate of } \\
\text { Undetected }\end{array}$ & $\begin{array}{c}\text { LTA } \\
(\mathbf{m g} / \mathbf{L})\end{array}$ & $\begin{array}{c}\text { No. of } \\
\text { WWTPs }\end{array}$ & $\begin{array}{c}\text { Number of } \\
\text { Samples }\end{array}$ & $\begin{array}{c}\text { Rate of } \\
\text { Undetected }\end{array}$ & $\begin{array}{c}\text { LTA } \\
(\mathbf{m g} / \mathbf{L})\end{array}$ \\
\hline 1 & 38 & $18.4 \%$ & 0.0008 & 57 & 18 & $0.0 \%$ & 0.0099 \\
2 & 36 & $8.3 \%$ & 0.0010 & 58 & 17 & $0.0 \%$ & 0.0018 \\
3 & 30 & $13.3 \%$ & 0.0040 & 59 & 13 & $0.0 \%$ & 0.0008 \\
4 & 25 & $64.0 \%$ & 0.0005 & 60 & 18 & $27.8 \%$ & 0.0010 \\
5 & 24 & $70.8 \%$ & 0.0004 & 61 & 10 & $0.0 \%$ & 0.0024 \\
6 & 23 & $13.0 \%$ & 0.0007 & 62 & 18 & $0.0 \%$ & 0.0080 \\
7 & 24 & $70.8 \%$ & 0.0004 & 63 & 18 & $0.0 \%$ & 0.0008 \\
8 & 23 & $26.1 \%$ & 0.0010 & 64 & 18 & $22.2 \%$ & 0.0019 \\
9 & 23 & $0.0 \%$ & 0.0029 & 65 & 16 & $0.0 \%$ & 0.0011 \\
10 & 24 & $58.3 \%$ & 0.0019 & 66 & 16 & $6.3 \%$ & 0.0006 \\
11 & 24 & $58.3 \%$ & 0.0005 & 67 & 17 & $58.8 \%$ & 0.0007 \\
\hline
\end{tabular}


Table 8. Cont.

\begin{tabular}{|c|c|c|c|c|c|c|c|}
\hline $\begin{array}{c}\text { No. of } \\
\text { WWTPs }\end{array}$ & $\begin{array}{c}\text { Number of } \\
\text { Samples }\end{array}$ & $\begin{array}{c}\text { Rate of } \\
\text { Undetected }\end{array}$ & $\begin{array}{c}\text { LTA } \\
(\mathrm{mg} / \mathrm{L})\end{array}$ & $\begin{array}{c}\text { No. of } \\
\text { WWTPs }\end{array}$ & $\begin{array}{c}\text { Number of } \\
\text { Samples }\end{array}$ & $\begin{array}{c}\text { Rate of } \\
\text { Undetected }\end{array}$ & $\begin{array}{c}\text { LTA } \\
(\mathrm{mg} / \mathrm{L})\end{array}$ \\
\hline 12 & 23 & $4.3 \%$ & 0.0023 & 68 & 11 & $45.5 \%$ & 0.0009 \\
\hline 13 & 23 & $52.2 \%$ & 0.0009 & 69 & 15 & $0.0 \%$ & 0.0012 \\
\hline 14 & 23 & $4.3 \%$ & 0.0011 & 70 & 15 & $26.7 \%$ & 0.0009 \\
\hline 15 & 22 & $0.0 \%$ & 0.0012 & 71 & 9 & $33.3 \%$ & 0.0005 \\
\hline 16 & 22 & $36.4 \%$ & 0.0007 & 72 & 14 & $71.4 \%$ & 0.0004 \\
\hline 17 & 11 & $0.0 \%$ & 0.0019 & 73 & 13 & $0.0 \%$ & 0.0031 \\
\hline 18 & 22 & $9.1 \%$ & 0.0016 & 74 & 13 & $0.0 \%$ & 0.0011 \\
\hline 19 & 22 & $22.7 \%$ & 0.0009 & 75 & 9 & $11.1 \%$ & 0.0009 \\
\hline 20 & 17 & $0.0 \%$ & 0.0011 & 76 & 12 & $75.0 \%$ & 0.0005 \\
\hline 21 & 22 & $4.5 \%$ & 0.0010 & 77 & 12 & $8.3 \%$ & 0.0013 \\
\hline 22 & 22 & $68.2 \%$ & 0.0006 & 78 & 12 & $50.0 \%$ & 0.0014 \\
\hline 23 & 22 & $0.0 \%$ & 0.0009 & 79 & 12 & $50.0 \%$ & 0.0010 \\
\hline 24 & 22 & $63.6 \%$ & 0.0004 & 80 & 10 & $0.0 \%$ & 0.0016 \\
\hline 25 & 22 & $72.7 \%$ & 0.0017 & 81 & 10 & $60.0 \%$ & 0.0004 \\
\hline 26 & 20 & $0.0 \%$ & 0.0033 & 82 & 9 & $55.6 \%$ & 0.0009 \\
\hline 27 & 22 & $0.0 \%$ & 0.0015 & 83 & 9 & $0.0 \%$ & 0.0010 \\
\hline 28 & 16 & $6.3 \%$ & 0.0040 & 84 & 9 & $0.0 \%$ & 0.0013 \\
\hline 29 & 22 & $72.7 \%$ & 0.0003 & 85 & 7 & $0.0 \%$ & 0.0012 \\
\hline 30 & 22 & $4.5 \%$ & 0.0250 & 86 & 9 & $0.0 \%$ & 0.0041 \\
\hline 31 & 22 & $9.1 \%$ & 0.0012 & 87 & 9 & $0.0 \%$ & 0.0063 \\
\hline 32 & 15 & $0.0 \%$ & 0.0012 & 88 & 9 & $0.0 \%$ & 0.0018 \\
\hline 33 & 18 & $0.0 \%$ & 0.0013 & 89 & 8 & $0.0 \%$ & 0.0018 \\
\hline 34 & 21 & $9.5 \%$ & 0.0014 & 90 & 9 & $55.6 \%$ & 0.0005 \\
\hline 35 & 15 & $80.0 \%$ & 0.0003 & 91 & 9 & $11.1 \%$ & 0.0007 \\
\hline 36 & 11 & $9.1 \%$ & 0.0019 & 92 & 9 & $0.0 \%$ & 0.0022 \\
\hline 37 & 21 & $23.8 \%$ & 0.0028 & 93 & 9 & $0.0 \%$ & 0.0016 \\
\hline 38 & 21 & $71.4 \%$ & 0.0003 & 94 & 7 & $57.1 \%$ & 0.0003 \\
\hline 39 & 20 & $0.0 \%$ & 0.0018 & 95 & 7 & $0.0 \%$ & 0.0050 \\
\hline 40 & 21 & $0.0 \%$ & 0.0018 & 96 & 9 & $0.0 \%$ & 0.0010 \\
\hline 41 & 21 & $47.6 \%$ & 0.0008 & 97 & 7 & $0.0 \%$ & 0.0010 \\
\hline 42 & 20 & $85.0 \%$ & 0.0003 & 98 & 7 & $0.0 \%$ & 0.0093 \\
\hline 43 & 21 & $9.5 \%$ & 0.0021 & 99 & 9 & $0.0 \%$ & 0.0035 \\
\hline 44 & 21 & $0.0 \%$ & 0.0008 & 100 & 8 & $0.0 \%$ & 0.0010 \\
\hline 45 & 21 & $0.0 \%$ & 0.0010 & 101 & 9 & $11.1 \%$ & 0.0013 \\
\hline 46 & 15 & $20.0 \%$ & 0.0010 & 102 & 8 & $25.0 \%$ & 0.0014 \\
\hline 47 & 21 & $0.0 \%$ & 0.0019 & 103 & 9 & $33.3 \%$ & 0.0078 \\
\hline 48 & 21 & $0.0 \%$ & 0.0064 & 104 & 9 & $0.0 \%$ & 0.0013 \\
\hline 49 & 21 & $0.0 \%$ & 0.0014 & 105 & 9 & $0.0 \%$ & 0.0022 \\
\hline 50 & 13 & $0.0 \%$ & 0.0029 & 106 & 9 & $11.1 \%$ & 0.0015 \\
\hline 51 & 20 & $5.0 \%$ & 0.0008 & 107 & 8 & $37.5 \%$ & 0.0017 \\
\hline 52 & 18 & $5.6 \%$ & 0.0013 & 108 & 8 & $50.0 \%$ & 0.0006 \\
\hline 53 & 14 & $0.0 \%$ & 0.0011 & 109 & 8 & $0.0 \%$ & 0.0072 \\
\hline 54 & 15 & $0.0 \%$ & 0.0014 & 110 & 7 & $57.1 \%$ & 0.0006 \\
\hline 55 & 10 & $10.0 \%$ & 0.0009 & 111 & 7 & $0.0 \%$ & 0.0011 \\
\hline 56 & 19 & $0.0 \%$ & 0.0015 & 112 & 7 & $0.0 \%$ & 0.0020 \\
\hline
\end{tabular}

\subsubsection{Daily Maximum Variability Factors}

Based on the delta-lognormal distribution of $\mathrm{Hg}$ and As discharge concentrations, the daily maximum variability factors were calculated while using the following equations:

$$
\mathrm{VF}(1)=\frac{\hat{P}_{99}}{\hat{E}(X)}
$$

where:

When $\delta \geq 0.99, \hat{P}_{99}=D$; When $\delta<0.99, \hat{P}_{99}=\max \left(D, e^{\mu+z \sigma}\right)$

$$
\hat{E}(x)=\hat{\delta} D+(1-\hat{\delta}) e^{\hat{\mu}+0.5 \hat{\sigma}^{2}}
$$

and,

$$
\begin{gathered}
\hat{\mu}=\frac{1}{n} \sum_{i-1}^{n} y_{i} \\
\hat{\sigma}^{2}=\sum_{i=1}^{n}\left(y_{i}-\hat{\mu}\right)^{2} /(n-1)
\end{gathered}
$$




$$
z=\varphi^{-1}\left(\frac{0.99-\delta}{1-\delta}\right)
$$

where:

$\mathrm{VF}(1)$-daily maximum variable factor;

$\hat{P}_{99}$ - estimated 99th percentile of $\mathrm{Hg}$ or As discharge concentration at a given plant;

$\hat{E}(x)$-estimated expected value of $\mathrm{Hg}$ or As discharge concentration at a given plant;

$y_{i}$-natural logarithm of $\mathrm{Hg}$ or As discharge concentration other than ND;

$\phi$-normal cumulated distribution function value.

Based on the method described above, the Hg daily maximum variable factors for 99 WWTPs and As daily maximum variable factors for 112 WWTPs are shown in Tables 9 and 10. As shown in the tables, it can find that the $\mathrm{Hg}$ daily maximum variable factors are 1.34-11.07 with an average of 3.89 and medium of 3.33. The As daily maximum variable factors are 1.44-16.05 with an average of 3.77 and medium of 3.35 .

Table 9. VF(1)s and derived discharge limits of $\mathrm{Hg}$ for 99 WWTPs.

\begin{tabular}{|c|c|c|c|c|c|}
\hline No. of WWTPs & $\mathrm{VF}(1)$ & Discharge Limit (mg/L) & No. of WWTPs & VF(1) & Discharge Limit (mg/L) \\
\hline 1 & 6.09 & 0.00042 & 51 & 8.40 & 0.00096 \\
\hline 2 & 9.00 & 0.00087 & 52 & 2.23 & 0.00012 \\
\hline 3 & 7.78 & 0.00317 & 53 & 3.80 & 0.00027 \\
\hline 4 & 3.72 & 0.00030 & 54 & 2.72 & 0.00013 \\
\hline 5 & 2.67 & 0.00020 & 55 & 2.81 & 0.00014 \\
\hline 6 & 6.42 & 0.00078 & 56 & 3.86 & 0.00054 \\
\hline 7 & 2.92 & 0.00020 & 57 & 5.05 & 0.00069 \\
\hline 8 & 1.75 & 0.00009 & 58 & 6.23 & 0.00066 \\
\hline 9 & 3.88 & 0.00026 & 59 & 1.55 & 0.00007 \\
\hline 10 & 3.82 & 0.00032 & 60 & 7.41 & 0.00138 \\
\hline 11 & 6.51 & 0.00060 & 61 & 6.16 & 0.00066 \\
\hline 12 & 3.52 & 0.00027 & 62 & 3.62 & 0.00028 \\
\hline 13 & 5.92 & 0.00158 & 63 & 3.00 & 0.00096 \\
\hline 14 & 2.62 & 0.00021 & 64 & 3.97 & 0.00022 \\
\hline 15 & 2.84 & 0.00013 & 65 & 2.19 & 0.00016 \\
\hline 16 & 5.42 & 0.00177 & 66 & 5.83 & 0.00055 \\
\hline 17 & 2.77 & 0.00016 & 67 & 3.68 & 0.00030 \\
\hline 18 & 3.57 & 0.00034 & 68 & 6.34 & 0.00051 \\
\hline 19 & 4.02 & 0.00044 & 69 & 2.93 & 0.00017 \\
\hline 20 & 2.25 & 0.00011 & 70 & 3.20 & 0.00088 \\
\hline 21 & 3.02 & 0.00026 & 71 & 6.01 & 0.00228 \\
\hline 22 & 2.46 & 0.00020 & 72 & 5.41 & 0.00082 \\
\hline 23 & 3.49 & 0.00158 & 73 & 2.28 & 0.00012 \\
\hline 24 & 3.58 & 0.00029 & 74 & 3.52 & 0.00182 \\
\hline 25 & 3.02 & 0.00018 & 75 & 5.42 & 0.00411 \\
\hline 26 & 4.25 & 0.00031 & 76 & 3.33 & 0.00087 \\
\hline 27 & 1.82 & 0.00008 & 77 & 2.07 & 0.00019 \\
\hline 28 & 2.29 & 0.00017 & 78 & 3.12 & 0.00050 \\
\hline 29 & 1.52 & 0.00012 & 79 & 4.77 & 0.00114 \\
\hline 30 & 1.81 & 0.00045 & 80 & 2.01 & 0.00029 \\
\hline 31 & 2.28 & 0.00011 & 81 & 2.27 & 0.00036 \\
\hline 32 & 5.22 & 0.00058 & 82 & 8.83 & 0.00082 \\
\hline 33 & 3.44 & 0.00035 & 83 & 2.45 & 0.00033 \\
\hline 34 & 2.70 & 0.00030 & 84 & 2.18 & 0.00054 \\
\hline 35 & 2.10 & 0.00015 & 85 & 2.07 & 0.00012 \\
\hline 36 & 3.81 & 0.00095 & 86 & 2.44 & 0.00014 \\
\hline 37 & 2.67 & 0.00059 & 87 & 3.74 & 0.00065 \\
\hline 38 & 2.43 & 0.00084 & 88 & 4.26 & 0.00090 \\
\hline 39 & 3.97 & 0.00105 & 89 & 2.63 & 0.00024 \\
\hline 40 & 4.42 & 0.00035 & 90 & 2.32 & 0.00013 \\
\hline 41 & 6.23 & 0.00071 & 91 & 2.09 & 0.00060 \\
\hline 42 & 3.27 & 0.00061 & 92 & 1.59 & 0.00008 \\
\hline 43 & 2.42 & 0.00013 & 93 & 2.65 & 0.00070 \\
\hline 44 & 2.48 & 0.00013 & 94 & 4.34 & 0.00109 \\
\hline 45 & 5.09 & 0.00091 & 95 & 8.71 & 0.00194 \\
\hline 46 & 3.22 & 0.00019 & 96 & 3.78 & 0.00036 \\
\hline 47 & 3.95 & 0.00022 & 97 & 1.34 & 0.00007 \\
\hline 48 & 3.52 & 0.00062 & 98 & 8.49 & 0.00108 \\
\hline 49 & 4.68 & 0.00026 & 99 & 1.85 & 0.00010 \\
\hline 50 & 11.07 & 0.00902 & & & \\
\hline
\end{tabular}


Table 10. VF(1)s and derived discharge limits of As for 112 WWTPs.

\begin{tabular}{|c|c|c|c|c|c|}
\hline No. of WWTPs & VF(1) & Discharge Limit (mg/L) & No. of WWTPs & VF(1) & Discharge Limit (mg/L) \\
\hline 1 & 3.15 & 0.0024 & 57 & 2.47 & 0.0244 \\
\hline 2 & 3.00 & 0.0029 & 58 & 3.26 & 0.0059 \\
\hline 3 & 7.68 & 0.0310 & 59 & 1.73 & 0.0013 \\
\hline 4 & 4.20 & 0.0020 & 60 & 4.17 & 0.0040 \\
\hline 5 & 2.34 & 0.0008 & 61 & 3.37 & 0.0081 \\
\hline 6 & 2.42 & 0.0017 & 62 & 8.15 & 0.0654 \\
\hline 7 & 2.99 & 0.0013 & 63 & 1.46 & 0.0012 \\
\hline 8 & 4.07 & 0.0039 & 64 & 5.50 & 0.0107 \\
\hline 9 & 2.99 & 0.0086 & 65 & 1.53 & 0.0017 \\
\hline 10 & 8.43 & 0.0163 & 66 & 3.35 & 0.0021 \\
\hline 11 & 4.23 & 0.0022 & 67 & 5.48 & 0.0036 \\
\hline 12 & 5.66 & 0.0129 & 68 & 7.69 & 0.0073 \\
\hline 13 & 3.47 & 0.0030 & 69 & 1.96 & 0.0024 \\
\hline 14 & 3.76 & 0.0043 & 70 & 3.67 & 0.0032 \\
\hline 15 & 1.93 & 0.0023 & 71 & 2.17 & 0.0012 \\
\hline 16 & 5.40 & 0.0037 & 72 & 2.41 & 0.0009 \\
\hline 17 & 2.63 & 0.0050 & 73 & 2.42 & 0.0075 \\
\hline 18 & 2.68 & 0.0043 & 74 & 3.43 & 0.0038 \\
\hline 19 & 4.35 & 0.0041 & 75 & 2.96 & 0.0027 \\
\hline 20 & 3.36 & 0.0038 & 76 & 3.54 & 0.0017 \\
\hline 21 & 3.97 & 0.0038 & 77 & 4.82 & 0.0062 \\
\hline 22 & 7.17 & 0.0042 & 78 & 4.37 & 0.0061 \\
\hline 23 & 2.56 & 0.0023 & 79 & 6.17 & 0.0059 \\
\hline 24 & 2.18 & 0.0008 & 80 & 4.01 & 0.0064 \\
\hline 25 & 16.05 & 0.0266 & 81 & 1.64 & 0.0006 \\
\hline 26 & 4.99 & 0.0163 & 82 & 5.70 & 0.0054 \\
\hline 27 & 4.04 & 0.0062 & 83 & 2.25 & 0.0022 \\
\hline 28 & 5.87 & 0.0233 & 84 & 3.43 & 0.0045 \\
\hline 29 & 1.64 & 0.0005 & 85 & 2.71 & 0.0031 \\
\hline 30 & 5.92 & 0.1482 & 86 & 6.35 & 0.0263 \\
\hline 31 & 3.41 & 0.0040 & 87 & 4.64 & 0.0291 \\
\hline 32 & 2.76 & 0.0033 & 88 & 2.92 & 0.0053 \\
\hline 33 & 1.86 & 0.0025 & 89 & 2.27 & 0.0041 \\
\hline 34 & 3.30 & 0.0047 & 90 & 3.30 & 0.0015 \\
\hline 35 & 1.44 & 0.0005 & 91 & 2.16 & 0.0016 \\
\hline 36 & 5.61 & 0.0108 & 92 & 5.28 & 0.0114 \\
\hline 37 & 2.61 & 0.0073 & 93 & 2.04 & 0.0033 \\
\hline 38 & 1.81 & 0.0006 & 94 & 1.44 & 0.0005 \\
\hline 39 & 2.62 & 0.0046 & 95 & 3.17 & 0.0158 \\
\hline 40 & 3.58 & 0.0064 & 96 & 2.06 & 0.0021 \\
\hline 41 & 3.75 & 0.0029 & 97 & 2.33 & 0.0023 \\
\hline 42 & 2.53 & 0.0008 & 98 & 5.09 & 0.0473 \\
\hline 43 & 5.57 & 0.0118 & 99 & 5.69 & 0.0201 \\
\hline 44 & 1.54 & 0.0012 & 100 & 2.04 & 0.0020 \\
\hline 45 & 2.07 & 0.0021 & 101 & 3.77 & 0.0051 \\
\hline 46 & 5.45 & 0.0054 & 102 & 4.54 & 0.0062 \\
\hline 47 & 2.50 & 0.0048 & 103 & 10.25 & 0.0799 \\
\hline 48 & 3.93 & 0.0252 & 104 & 3.31 & 0.0043 \\
\hline 49 & 3.98 & 0.0056 & 105 & 3.21 & 0.0072 \\
\hline 50 & 3.86 & 0.0112 & 106 & 4.93 & 0.0075 \\
\hline 51 & 2.43 & 0.0019 & 107 & 2.98 & 0.0050 \\
\hline 52 & 3.50 & 0.0046 & 108 & 4.34 & 0.0028 \\
\hline 53 & 3.00 & 0.0032 & 109 & 5.70 & 0.0410 \\
\hline 54 & 2.34 & 0.0033 & 110 & 3.24 & 0.0020 \\
\hline 55 & 4.02 & 0.0037 & 111 & 2.03 & 0.0021 \\
\hline 56 & 3.48 & 0.0053 & 112 & 1.78 & 0.0036 \\
\hline
\end{tabular}

\subsubsection{Discharge Limits}

We obtained the Hg and As discharge limits for each WWTP (Tables 9 and 10) while using Equation (1). From these results, it can find that the $\mathrm{Hg}$ discharge limits are $0.00007-0.00902 \mathrm{mg} / \mathrm{L}$ with an average of $0.00067 \mathrm{mg} / \mathrm{L}$ and medium of $0.00035 \mathrm{mg} / \mathrm{L}$. These values are lower than the limit $(0.001 \mathrm{mg} / \mathrm{L})$ in GB 18918-2002. Derived discharge limits for As are 0.0005-0.1482 mg/L with an average of $0.0092 \mathrm{mg} / \mathrm{L}$ and medium of $0.0041 \mathrm{mg} / \mathrm{L}$, which are also lower than the limit $(0.1 \mathrm{mg} / \mathrm{L})$ in GB 18918-2002. When considering that the national discharge limits should be suitable for the entire country, we used the medium value of LTAs and average value of VF(1)s as the suggested $\mathrm{Hg}$ and As discharge limits [11] (Table 11). 
Table 11. Suggested $\mathrm{Hg}$ and As discharge limits of WWTPs in China.

\begin{tabular}{cccc}
\hline Pollutant & Medium of LTAs $\mathbf{( m g / L )}$ & Average of VF(1)s & Suggested Discharge Limit (mg/L) \\
\hline $\mathrm{Hg}$ & 0.00009 & 3.89 & 0.00035 \\
$\mathrm{As}$ & 0.0012 & 3.77 & 0.0045 \\
\hline
\end{tabular}

\section{Conclusions}

This study analyzed the discharge characteristics of 14 heavy metals and metalloids at WWTPs in China. The study used $\mathrm{Hg}$ and As as an example to derive the discharge limits based on statistical methods. In this study, 13 of the 14 heavy metals and metalloids, with the exception of alkyl mercury, were detected in the discharge water with high rates of detection of $\mathrm{As}, \mathrm{Cu}, \mathrm{Mn}$, and $\mathrm{Se}$. In many cases, $\mathrm{Cr}, \mathrm{Cr}^{6+}, \mathrm{Pb}$, and $\mathrm{Ni}$ exceeded standards. Removal rates of $\mathrm{Hg}$, As, $\mathrm{Cd}, \mathrm{Cr}, \mathrm{Cr}^{6+}, \mathrm{Pb}, \mathrm{Ni}, \mathrm{Cu}, \mathrm{Zn}, \mathrm{Mn}$, and Se exceeded $40 \%$, which is consistent with values in other countries.

Results from this study suggest that the delta-lognormal distribution was suitable for the heavy metal and metalloid discharge concentrations of WWTPs. Based on the statistical distribution, the study found that geographic location was strongly correlated with $\mathrm{Hg}$ and As discharge concentrations, while size and influent concentration were not. The derived LTAs for Hg of 99 WWTPs and As of 112 WWTPs showed that they were much lower than the limits in GB 18918-2002. The derived VF(1)s of WWTPs revealed that the $\mathrm{Hg}$ and As fluctuations were not large, suggesting that WWTPs in China are relatively well-managed. Lastly, the derived $\mathrm{Hg}$ and As discharge limits suggest that it is necessary to establish 1-2 orders of magnitude lower discharge limits for WWTPs in China.

Author Contributions: Methodology, Y.Z. (Yuhua Zhou) and H.F.; Writing-Original Draft Preparation, Y.Z. (Yuhua Zhou), J.L., Y.Z. (Yu Zhang), J.Z. and Y.L.; Writing-Review \& Editing, H.F. and X.W.

Funding: This research received no external funding.

Conflicts of Interest: The authors declare no conflict of interest.

\section{References}

1. EU. Pollutants in Urban Waste Water and Sewage Sludge; European Communities: Luxembourg, 2001.

2. Oliver, B.G.; Cosgrove, E.G. Metal concentrations in the sewage, effluents, and sludge of some southern Ontario wastewater treatment plants. Environ. Lett. 1975, 9, 75-90. [CrossRef] [PubMed]

3. Li, P.; Fan, J.H.; Liu, R.; Yu, B.; Cheng, J.D.; Yu, S.L.; Chen, L.J.; Shan, X.L. A study on pollution characteristics and removal performance of heavy metals in a tannery and textile dyeing industrial park wastewater treatment plant. Environ. Eng. 2012, 30, 101-108.

4. Ministry of Ecology and Environment of China. Integrated Wastewater Discharge Standard (GB 8978-1996); Ministry of Ecology and Environment of the People's Republic of China: Beijing, China, 1996. Available online: http:/ / www.mee.gov.cn (accessed on 15 May 2018).

5. Ministry of Ecology and Environment of China. Discharge Standard of Pollutants for Municipal Wastewater Treatment Plant (GB 18918-2002); Ministry of Ecology and Environment of the People's Republic of China: Beijing, China, 2002. Available online: http:/ / www.mee.gov.cn (accessed on 15 May 2018).

6. Ma, S.H.; He, X.H. The brief introduction of discharge standard of urban wastewater treatment plant (GB 18918-2002). Water Wastew. Eng. 2003, 29, 89-94. (In Chinese)

7. Zhou, Y.H.; Lu, Y.N.; Zhang, Y.; Zhu, J.; Lei, J.; Shen, C.; Wu, X.F. Assessment on the COD discharge status of municipal wastewater treatment plant in a city of China. Environ. Sci. 2014, 35, 3998-4002.

8. Zhou, Y.H.; Lu, Y.N.; Zhang, Y.; Ren, N.; Lei, J. Assessment on daily discharge status of regular water pollutants in urban sewage treatment plant. Ind. Water Treat. 2016, 36, 12-15. (In Chinese)

9. Zhou, Y.H.; Duan, N.; Wu, X.F.; Fang, H. COD discharge limits for urban wastewater treatment plants in China based on statistical methods. Water 2018, 10, 777. [CrossRef]

10. Environment Statistical Annual Report 2015; Ministry of Environment Protection of China: Beijing, China, 2015. Available online: http: / / www.mee.gov.cn (accessed on 15 May 2018).

11. Kahn, H.D.; Rubin, M.B. Use of statistical methods in industrial water pollution control regulations in the United States. Environ. Monit. Assess. 1989, 13, 129-148. [CrossRef] [PubMed] 
12. Ministry of Ecology and Environment of China. Water Quality-Determination of Mercury, Arsenic, Selenium, Bismuth and Antimony-Atomic Fluorescence Spectrometry (HJ 694-2014); Ministry of Ecology and Environment of the People's Republic of China: Beijing, China, 2014. Available online: http:/ / www.mee.gov.cn (accessed on 31 July 2018).

13. Ministry of Ecology and Environment of China. Water Quality-Determination of Alkyl Mercury-Gas Chromatography (GB/T 14204-93); Ministry of Ecology and Environment of the People's Republic of China: Beijing, China, 1993. Available online: http:/ / www.mee.gov.cn (accessed on 31 July 2018).

14. Ministry of Ecology and Environment of China. Water Quality-Determination of Cadmium-Spectrophotometric Method with Dithlzone (GB 7471-87); Ministry of Ecology and Environment of the People's Republic of China: Beijing, China, 1987. Available online: http:/ / www.mee.gov.cn (accessed on 31 July 2018).

15. Ministry of Ecology and Environment of China. Water Quality-Determination of Total Chromium (GB 7466-87); Ministry of Ecology and Environment of the People's Republic of China: Beijing, China, 1987. Available online: http:/ / www.mee.gov.cn (accessed on 31 July 2018).

16. Ministry of Ecology and Environment of China. Water Quality-Determination of Chromium (VI) (GB 7467-87); Ministry of Ecology and Environment of the People's Republic of China: Beijing, China, 1987. Available online: http:/ / www.mee.gov.cn (accessed on 31 July 2018).

17. Ministry of Ecology and Environment of China. Water Quality-Determination of Lead-Spectrophotometric Method with Dithizone (GB/T 7470-1987); Ministry of Ecology and Environment of the People's Republic of China: Beijing, China, 1987. Available online: http:/ / www.mee.gov.cn (accessed on 31 July 2018).

18. Ministry of Ecology and Environment of China. Water Quality-Determination of Nickel-Flame Atomic Absorption Spectrometric Method (GB11912-89); Ministry of Ecology and Environment of the People's Republic of China: Beijing, China, 1989. Available online: http:/ / www.mee.gov.cn (accessed on 31 July 2018).

19. Ministry of Ecology and Environment of China. Water Quality-Determination of Beryllium-Graphite Furnace Atomic Absorption Spectrophotometry (HJ/T59-2000); Ministry of Ecology and Environment of the People's Republic of China: Beijing, China, 2000. Available online: http:/ / www.mee.gov.cn (accessed on 31 July 2018).

20. Ministry of Ecology and Environment of China. Water Quality-Determination of 65 Elements-Inductively Coupled Plasma-Mass Spectrometry (HJ 700-2014); Ministry of Ecology and Environment of the People's Republic of China: Beijing, China, 2014. Available online: http:/ / www.mee.gov.cn (accessed on 31 July 2018).

21. Ministry of Ecology and Environment of China. Water Quality-Determination of Copper-Sodium Diethylthiocabamate Spectrophotometric Method (HJ 485-2009); Ministry of Ecology and Environment of the People's Republic of China: Beijing, China, 2009. Available online: http:/ / www.mee.gov.cn (accessed on 31 July 2018).

22. Ministry of Ecology and Environment of China. Water Quality-Ditermination of Copper, Zinc, Lead and Cadmium-Atomic Absorption Spectrometry (GB 7475-87); Ministry of Ecology and Environment of the People's Republic of China: Beijing, China, 1987. Available online: http:/ / www.mee.gov.cn (accessed on 31 July 2018).

23. Ministry of Ecology and Environment of China. Water Quality-Determination of Iron and Manganese-Flame Atomic Absorption Spectrometric Method (GB 11911-89); Ministry of Ecology and Environment of the People's Republic of China: Beijing, China, 1989. Available online: http:/ / www.mee.gov.cn (accessed on 31 July 2018).

24. Ministry of Ecology and Environment of China. Water Quality-Determination of Selemium-Diaminonaphthalene Fluorometric Method (GB 11902-89); Ministry of Ecology and Environment of the People's Republic of China: Beijing, China, 1989. Available online: http:/ / www.mee.gov.cn (accessed on 31 July 2018).

25. US EPA. Development Document for Effluent Limitations Guidelines and Standards for the Organic Chemicals, Plastics and Synthetic Fibers Point Source Category; United States Environmental Protection Agency: Washington, WA, USA, 1987.

26. Gbondo-Tugbawa, S.S.; McAlear, J.A.; Driscoll, C.T.; Sharpe, C.W. Total and methyl mercury transformations and mass loadings within a wastewater treatment plant and the impact of the effluent discharge to an alkaline hyper eutrophic lake. Water Res. 2010, 44, 2863-2875. [CrossRef] [PubMed]

27. Da Silva Oliveira, A.; Bocio, A.; Trevilato, T.M.B.; Takayanagui, A.M.M.; Domingo, J.L.; Segura-Muñoz, S.I. Heavy metals in untreated/treated urban effluent and sludge from a biological wastewater treatment plant. Environ. Sci. Pollut. Res. Int. 2007, 14, 483-489. [CrossRef]

28. Busetti, F.; Badoer, S.; Cuomo, M.; Rubino, B.; Traverso, P. Occurrence and removal of potentially toxic metals and heavy metals in the wastewater treatment plant of Fusina (Venice, Italy). Ind. Eng. Chem. Res. 2005, 44, 9264-9272. [CrossRef] 
29. Kulbat, E.; Olanczuk, K.; Quant, B.; Geneja, M.; Haustein, E. Heavy metals removal in the mechanical-biological wastewater treatment plant "Wschód" in Gdańsk. Pol. J. Environ. Stud. 2003, 12, 635-641.

30. Onchoke, K.K.; Sasu, S.A. Determination of hexavalent Chromium (Cr(VI)) concentrations via ion chromatography and UV-Vis spectrophotometry in samples collected from Nacogdoches wastewater treatment plant, East Texas (USA). Adv. Environ. Chem. 2016. [CrossRef]

31. Diaz, J.P.; Navarro, M.; Lbpez, H.; Lbpez, M.C. Selenium (IV) and (VI) levels in potable, irrigation and waste waters from an industrial zone in southeastern Spain. Sci. Total Environ. 1996, 186, 231-236. [CrossRef]

32. Obarska-Pempkowiak, H. Zanieczyszczenie środowiskanaturalnego metalami ciężkimi jako kryterium rolniczegowykorzystania osadów ściekowych, Zeszyty Naukowe Politechniki Gdańskiej. Budownictwo Wodne XXXV 1992, 473, 73-99.

33. Kim, I.; Hong, S.-H.; Jung, J.-Y. Establishment of effluent Standards for industrial wastewaters in Korea: Current issues and suggestions for future plan. J. Water Environ. Technol. 2010, 8, 151-165. [CrossRef]

34. US EPA. Development Document for Final Effluent Limitations Guidelines and Standards for the Pharmaceutical Manufacturing Point Source Category; Office of Water: Washington, WA, USA, 1998.

35. Balogh, S.J.; Nollet, Y.H. Methyl mercury input to the Mississippi River from a large metropolitan wastewater treatment plant. Sci. Total Environ. 2008, 406, 145-153. [CrossRef] [PubMed]

36. Li, H.; Mao, Y.X.; Li, Y.; Ma, Y.X.; Wang, X.Y.; Song, D.Y. Occurrence and mass balance of mercury at a sewage treatment plant. Part I: Total mercury. Environ. Chem. 2014, 33, 1059-1065.

37. Ministry of Ecology and Environment of China. Surface Water Environmental Quality Standards (GB 3838-2002); Ministry of Ecology and Environment of the People's Republic of China: Beijing, China, 2002. Available online: http:/ / www.mee.gov.cn (accessed on 31 July 2018).

38. Zhang, Y.H. The transformation of mercury in the sewage treatment plant and analysis of its speciation in sewage sludge. Guangzhou Chem. Ind. 2016, 44, 49-50. (In Chinese)

39. Bodaly, R.A.; Rudd, W.M.; Flett, R.J. Effect of urban sewage treatment on total and methyl mercury concentrations in effluents. Biogeochemistry 1998, 40, 279-291. [CrossRef]

40. Lu, J.W.; Chen, P.L.; Zhao, X.L. Study on the variation of heavy metals in the traditional municipal activated sludge wastewater treatment process. Environ. Pollut. Prev. 2008, 30, 29-32. (In Chinese) 